\title{
RETÓRICA DA IMAGEM E FORMAÇÃO DO VALOR-DE-GOZO'
}

\author{
Image rhetoric and the formation of jouissance
}

\begin{abstract}
Eliza Bachega Casadei
Mestranda em Ciências da Comunicação pela Escola de Comunicações e Artes da Universidade de São Paulo (ECA/USP), São Paulo - SP, Brasil, e-mail: elizacasadei@yahoo.com.br
\end{abstract}

\section{Resumo}

Ao tomar como premissa a instituição do consumo e do mais-de-olhar como os principais articuladores dos laços sociais, o objetivo do presente artigo é investigar a forma como a imagem se configura como meio para obtenção do mais-de-gozar imaginário. A partir da perspectiva de que a sociedade escópica esteja mais voltada para a sedução do que para o controle, serão utilizados os parâmetros da semiótica da imagem de Umberto Eco para estudar como, a partir de uma série de mecanismos retóricos de ordem metafórica e antonomásica, a imagem apela ao indivíduo, que em troca a transforma em mercadoria por meio da retribuição do olhar.

Palavras-chave: Valor de gozo. Mais-de-Olhar. Mídia. Mercadoria. Retórica da Imagem.

\begin{abstract}
Concerning the fact that the consumption and the surplus-gaze have become the main articulators of the social bonds, the objective of this article is to investigate how image configures itself as a way to obtain the imaginary surplus-pleasure. From the perspective that today's scopic society is more devoted to seduction than to control, the parameters of Umberto Eco's semiotic of image will be used to study how, from a serie of rhetoric mechanisms, image appeals the individual which, in return, transform this image in a commodity through retribution of the glance.
\end{abstract}

Keywords: Jouissance. Surplus-gaze. Media. Commodity. Image Rhetoric.

1 O presente trabalho foi realizado com o apoio do Conselho Nacional de Desenvolvimento Científico e Tecnológico (CNPq-Brasil). 


\section{INTRODUÇÃO}

\section{O consumo como laço social e o olhar como gozo}

As transformações sociais têm caminhado, segundo diversos autores, em direção à configuração de uma sociedade escópica. Ao elevar o mais-deolhar e o consumo como articuladores importantes dos laços sociais, esses autores diagnosticam a importância crescente da sedução frente ao controle e mostram como a imagem se torna um poderoso instrumento do mais-de-gozar imaginário. O objetivo do presente artigo é estudar a forma como esse se configura através de produções midiáticas, além de investigar como, a partir de uma série de mecanismos retóricos de ordem metafórica e antonomásica, a imagem apela ao indivíduo, que em troca a transforma em mercadoria por meio da retribuição do olhar.

Tal abordagem se justifica uma vez que as evoluções das práticas midiáticas marcam verdadeiras revoluções nos regimes de visualidades públicas. Para John B. Thompson, se antes do aperfeiçoamento das técnicas de impressão a visibilidade dos líderes dependia de uma interação face a face (e, portanto, restrita a privilegiados), com a invenção da imprensa a visibilidade é desvinculada da aparição física. "Os mandantes utilizaram-se dos novos meios de comunicação não só como um veículo para promulgar decretos oficiais, mas também como meio de construir uma imagem de si que poderia chegar a regiões afastadas" (THOMPSON, 2008, p. 22). A popularização das mídias eletrônicas hiperboliza o processo uma vez que permite que os mesmos sinais que compõem uma comunicação face a face possam ser percebidos mesmo quando os indivíduos estão separados no espaço e no tempo, inaugurando um regime de visualidades marcado pela ubiquidade e pela instantaneidade.

Ao mesmo tempo em que essa nova visibilidade facilita a autopromoção, ela também opera inversamente ao expor os líderes políticos ao escrutínio da opinião pública. E é a partir desse pressuposto que Thompson argumenta que a metáfora foucaultiana do Panóptico - que por tanto tempo serviu como explicação dos sistemas de vigilância da modernidade - deve ser invertida. Isso porque enquanto a prisão idealizada por Bentham faz com que muitos sejam visíveis para poucos, a mídia opera um movimento inverso: poucos se tornam vigiados por muitos. Haveria, portanto, uma quasi-interaçãomediada entre os líderes políticos e o público, promovida pela imprensa.

O filósofo Zygmunt Bauman também aponta para essa inadequação da metáfora do Panóptico para os tempos midiáticos atuais, porém, enfatizando os aspectos nitidamente mercadológicos envolvidos nos meios de comunicação de massa. Para entendermos essa inversão, é necessário alocá-la no contexto mais amplo de sua obra. Para o autor, a modernidade clássica era marcada por colocar o trabalho como o principal articulador das identidades, dos laços e das funções sociais, ou seja, você era o que você fazia para viver. Por contraste, em um habitat pós-moderno, você é o que você compra:

Para o sucesso desta educação para o consumo, o mundo se apresenta como uma imensa matriz de possibilidades, de sensações intensas e cada vez mais intensas, de experiências profundas e cada vez mais profundas... O mundo e todos os seus fragmentos são julgados pela sua capacidade de ocasionar sensações e... de incitar desejos... mais satisfatórios que a própria satisfação em si (BAUMAN, 1999 apud SMITH, 1999, p. 156-157).

Diante dessa reconfiguração de mundo, o papel das mídias também é radicalmente deslocado. Articuladores tradicionais de sentidos, tais como a Escola e o Estado, perderam o seu papel regulatório e foi "o capitalismo quem assumiu a tarefa de gerenciar as dimensões econômicas e culturais da sociedade. Seu meio primário de regulação é o mercado" (SMITH, 1999, p. 155).

A partir desses pressupostos, Bauman substitui a metáfora do Panóptico pela do Sinóptico, uma vez que, enquanto o primeiro se configura como um mecanismo de exclusão e controle, o outro é, essencialmente, um instrumento de aferição de privilégios para pessoas bem classificadas segundo os critérios e a lógica do consumo. Um banco de dados, por exemplo, poderia ser visto pela lógica foucaultiana como um instrumento de controle e vigilância nos moldes do Panóptico. Para Bauman, no entanto, seus mecanismos de funcionamento e suas consequências sociais são diferentes, uma vez que apontam para a formação de um clube de privilegiados: 
Com efeito, ser incluído no banco de dados é a condição primordial da credibilidade e este é o meio de acesso à melhor oportunidade local. O Panóptico laçava seus internos como produtores e/ou soldados, dos quais se esperava e exigia uma conduta monótona e rotineira; o banco de dados registra os consumidores confiáveis e dignos de crédito, eliminando todo o restante que não deve ser levado em conta no jogo do consumo simplesmente pelo fato de não haver nada a registrar sobre suas atividades. A principal função do Panóptico era garantir que ninguém pudesse escapar do espaço estreitamente vigiado. [...]. Ao contrário do Panóptico, o banco de dados é um veículo de mobilidade, não grilhões a imobilizar as pessoas (BAUMAN, 1999, p. 58-59).

No mundo do Sinóptico, os alvos deixaram de ser os vigiados e passaram a ser os vigilantes e, invertendo a lógica do Panóptico, os muitos vigiam os poucos. Se esse forçava as pessoas até a posição em que podiam ser vigiadas, o Sinóptico prescinde desse elemento coercitivo: ele seduz as pessoas à vigilância. E isso porque "os poucos que os vigilantes vigiam são estritamente selecionados" (BAUMAN, 1999, p. 60).

As produções midiáticas, nesse contexto, são postas dentro dessa lógica do banco de dados, uma vez que esses poucos vigiados são as pessoas autorizadas a penetrar nos meios de comunicação para transmitir um estilo de vida próprio. Como coloca Bauman:

De onde quer que venham, no entanto, todas as celebridades exibidas colocam em exibição o mundo das celebridades - um mundo cuja principal característica é precisamente a condição de ser observado... por muitos e em todos os cantos do globo, de ser global na sua qualidade de observado. O que quer que falem quando estão no ar, passam a mensagem de um estilo de vida total. A vida delas, o estilo de vida delas (BAUMAN, 1999, p. 61).

Uma vez que o consumo passa a ser o articulador das identidades e dos laços sociais e a mídia passa a operar como um dos principais veículos propagadores desses valores socialmente construídos, o preço a ser pago por quem está fora desse sistema é bastante alto: para Bauman, a punição para os pobres é sempre serem classificados como "sem significado" (ascription to meaninglessness).

Diante dessas configurações de mundo, os meios midiáticos não mais podem ser pensados como meros mediadores de informações, serviços ou mesmo entretenimento. Eles passam a atuar (também e/ou principalmente) como mediadores de bens de consumo que funcionam como passagens ou senhas em direção a um gozo imaginário (BUCCI, 2002a). E é justamente porque no capitalismo superindustrial, "na ordem do imaginário, o superego, em lugar de expressar a interdição do gozo, torna-se aquele que ordena o oposto: Goze!" - e nesse sentido 'goze' quer dizer: 'Consuma!' (BUCCI, 2002b, p. 261) -, que Eugenio Bucci pode afirmar que:

A estética da mercadoria, industrialmente, e, portanto, socialmente fabricada no imaginário, expressa-se pela imagem da mercadoria, que constitui o objeto de desejo para o sujeito, sendo dotada, nessa direção, de uma promessa de gozo cujo valor incide sobre o valor de troca da mercadoria. Isso implica falar da mercadoria em dois planos ou, no mínimo, implica falar da mercadoria como a resultante de um processo que justapõe duas mercadorias em uma só: a primeira é aquela de $O$ Capital, a coisa corpórea que tem valor de uso e valor de troca, a segunda é a sua imagem, fabricada fora da primeira, mas tendo a primeira como referente de partida (BUCCI, 2002b, p. 271).

Mas onde está localizado, afinal de contas, esse fora de que nos fala Bucci? Em um primeiro nível ele está alocado, obviamente, no imaginário, uma vez que os processos de significação ocorrem todos nesse âmbito. "É um erro supor que a mercadoria venha pronta de algum lugar externo ao imaginário. Ela se constrói, de fato, no imaginário e, mais exatamente, no imaginário social" (BUCCI, 2002b, p. 272). Em um aspecto menos óbvio, no entanto, ela está localizada - e é aí também que o gozo imaginário se realiza - no olhar social. "Sem o emprego do olhar social, o valor de gozo não existe. E o olhar social é comprado pelo capital do mesmo modo como a força de trabalho do operário de fábrica é comprada" (BUCCI, 2008b, p. 273).

Essa posição é consonante com a de Antonio Quinet (2002), para quem o mais-de-gozar 
encontra sua máxima expressão, na sociedade atual, em um mais-de-olhar, ou seja, "em suas duas valências, o olhar traz o prazer quando escamoteia a castração - preenchendo a falta-a-ser do sujeito, como falta fálica" (QUINET, 2002, p. 87). É a partir dessa noção do ser como faltante que se tem a ilusão da completude através da imagem. Segundo Quinet, na sociedade atual "não só se ama e se admira a celebridade como, no cogito da sociedade escópica, todos aspiram a sê-lo [...]: sou visto, logo existo. Visus ergo sum" (QUINET, 2002, p. 284).

É nesse mesmo sentido que Bucci (2002b, p. 276) afirma que o sujeito:

busca na televisão as imagens que o completam - que o informam, que o divertem, que o deliciam - imaginariamente. Goza por elas. Em troca, cede seu olhar durante intervalos para que se consolide no imaginário a imagem da mercadoria que aí, por seu olhar, obtém significação. A televisão tende a eliminar tudo o que seja interrupção desse gozo, de sorte que a linguagem publicitária fala como gozo ininterrupto. A programação da televisão é o prolongamento da linguagem publicitária e a linguagem publicitária é o prolongamento da programação: ambas se indiferenciam.

Assim, mesmo quando uma pessoa se diverte ela também está trabalhando; torna-se um trabalhador do olhar, na medida em que "o olhar 'trabalha' para produzir valor de gozo, assim como a operação das máquinas de entretenimento, um trabalho alienado no lazer, destina-se a produzir mais valor de gozo" (BUCCI, 2002b, p. 284).

Ao tomar essas afirmações como premissas, reiteramos que o objetivo do presente artigo é investigar a forma como a imagem se configura como expressão para a plena realização desse valor de gozo. Uma vez que a metáfora do Panóptico foi invertida, não podemos nos limitar à discussão de que a atual sociedade escópica teria uma fixação pelas imagens na medida em que elas reforçariam a vigilância. A partir da perspectiva de Bauman de que o controle hoje se exerce a partir da sedução, utilizaremos os parâmetros da semiótica da imagem de Umberto Eco para explicarmos como, a partir de uma série de mecanismos retóricos de ordem metafórica e antonomásica, a imagem apela ao indivíduo, que em troca a transforma em mercadoria através do olhar.
Para isso, precisamos pensar na forma como a imagem se torna sinônimo de índice do real na sociedade escópica.

\section{LEITURA EM IMAGENS: olhar como índice do real}

Como bem aponta Quinet (2002, p. 9), muitos movimentos filosóficos relegaram ao "olhar" um papel secundário. Em Descartes, por exemplo, o racionalismo abandona a imagem e o pensamento "não quis mais frequentar o visível" e "nada mais restou do mundo onírico da analogia". Dessa forma, teria sido a psicanálise que introduziu "na reflexão sobre o olhar humano uma dimensão que a ótica dos antigos abrigava, mas que a ótica geometral, da qual somos tributários na maior parte de nossa existência e de nosso pensamento, corre o risco de ocultar totalmente" (QUINET, 2002, p. 9). A preocupação com o olhar, portanto, é inquietação mais recente.

A obra de Vilém Flusser está inserida nesse contexto e busca, fundamentalmente, mecanismos que possam explicar as mudanças de código na História da Comunicação - preocupação essa que surge a partir da constatação de que a época atual, ao contrário das precedentes, é regida por imagens. De acordo com Flusser, a leitura em linha (formada por textos escritos) e a leitura em superfície (composta por imagens, fotografias, pinturas, etc.) proporcionam modos bastante distintos de apreensão do mundo.

A leitura em linha pode ser representada por "discursos de pontos", ou seja, "representam o mundo ao projetá-lo em uma série de sucessões" (FLUSSER, 2007, p. 102-103). Nesse sentido, tratase de uma leitura de processo, uma leitura histórica, na medida em que é necessário seguir o caminho imposto pelo texto (seguir a linha da esquerda para a direita e de cima para baixo) para apreendermos o seu significado.

$\mathrm{Na}$ leitura em superfície, o mecanismo é inteiramente outro: "ao lermos as linhas, seguimos uma estrutura que nos é imposta; quando lemos as pinturas, movemo-nos de certo modo livremente dentro da estrutura que nos foiimposta" (FLUSSER, 2007 , p. 104). A mensagem de uma imagem, ao contrário do texto que deve seguir determinado caminho, já pode ser apreendida em uma única olhadela geral, 
a partir de inúmeros caminhos do olhar possíveis, sem que um único trajeto deva ser necessariamente seguido para que possamos apreender o seu sentido.

O autor coloca que chegar até os fatos consiste num problema para os dois tipos de leitura (uma vez que a própria noção de "fato" é uma categoria do imaginário). No entanto, trata-se de um problema diferente para cada um deles. A leitura linear enfrenta a armadilha de que, a cada dia, ela ameaça perder mais o contato com a realidade que representa, desvinculando-se, na medida em que cria novos modelos de (re)apresentação do mundo, da experiência imediata do cotidiano. No caso das imagens, o problema está alocado no fato de que, quanto mais tecnicamente perfeitas elas se tornam, mais elas se deixam substituir pela realidade que, em origem, deveriam representar. Em outras palavras, as imagens são revestidas de um privilégio do "aconteceu", do "estar lá" e, com isso, criam a ilusão de substituir o real que representam. Em outros termos, "o mundo da ficção linear [...] está mostrando cada vez mais seu caráter fictício, meramente conceitual; e o mundo da ficção-em-superfície [...] está mascarando cada vez melhor seu caráter fictício" (FLUSSER, 2007, p. 116).

Se usarmos a terminologia de Roland Barthes, podemos afirmarque a imagem, para Flusser, é capaz de engendrar uma ilusão referencial e um efeito de real muito mais eficazmente do que outros tipos de suportes midiáticos não imagéticos. Para Barthes (1988), esse efeito é obtido através de uma aparente desarticulação da tripartidaridade do signo, em que o significado (enquanto estrutura imaginária) é tido como um elemento vergonhoso, passível de ser fundido ao referente. Essa correspondência imediata entre o significante e o referente cria uma ilusão referencial e um efeito de realidade na medida em que os discursos que deles se utilizam, ao se acreditarem revestidos pelos privilégios do aconteceu, também se outorgam o privilégio de encontrar o real que representam.

De acordo com Bucci, o Telespaço Público também tem essa característica como centro articulador. Isso porque "às figuras mutantes que se insinuam e se desfazem na tela eletrônica atribui-se uma autoridade de índices do real - e eis que delas a realidade se veste para dar-se a ver. A história se escreve assim, ou melhor, desenha-se assim, como visualidade" (BUCCI, 2002b, p. 29). Ao combinar visibilidade e ubiquidade, os fatos que pertencem à Instância da Imagem ao Vivo estão sempre “em acontecendo" e essa se torna mesmo "o altar contemporâneo da verdade factual possível, o seu plano mais alto e mais irreconhecível de registro" (BUCCI, 2002b, p. 29).

O advento de uma sociedade escópica, portanto, comporta um modo novo de apreensão do mundo e, sendo assim, precisamos estudar a forma como ela apela ao olhar para que possamos falar em uma formação do valor de gozo através das imagens. Para isso, precisamos pensar nas características próprias da imagem em relação aos textos escritos. A perspectiva de Umberto Eco a respeito das características da retórica da imagem é bastante interessante neste sentido.

\section{ARGUMENTAÇÃO EM IMAGENS: o olhar seduzido}

Diferentemente da perspectiva fenomenológica de Flusser, Umberto Eco (2007) explica as diferenças fundamentais entre os textos escritos e as imagens a partir de uma perspectiva semiótica. Para Eco, as imagens não podem ser estudadas tais como os signos. Isso porque, diferentemente dos textos, elas são formadas a partir de semas. O sema corresponde a uma espécie de signo particular, cuja significação corresponde não a um signo, mas a um enunciado da língua. Dessa forma,

o sinal de contramão, por exemplo, embora apareça como um signo visual dotado de significado unívoco, não pode ser reportado a um signo verbal equivalente, mas a um equivalente sintagma ('contramão'; ou então: 'é proibido passar por esta rua nesta direção’) (ECO, 2007, p. 137).

Os semas, portanto, se referem ao que conhecemos mais comumente como signos icônicos e constituem, com efeito, um enunciado icônico complexo. Eles são, ao mesmo tempo, a circunstância de comunicação que permite reconhecer o signo icônico e o sistema que os põe em oposição significante. "Podem, portanto, ser considerados - em relação aos signos cuja identificação permitem - um idioleto" (ECO, 2007, p. 137).

Esses enunciados trazidos pelas imagens, no entanto, podem ser bem mais complexos do 
que os trazidos pelo sinal da contramão. Eco traz o exemplo de um anúncio publicitário no qual uma mão estendida oferece um copo de cerveja transbordante, cuja superfície externa do vidro está revestida por um fino véu de vapor, produzindo a sensação de gelo. Embora não haja nem cerveja, nem gelo no papel em que está impressa a imagem, quando eu vejo o copo de cerveja, eu percebo os estímulos visuais e os coordeno até gerar-se uma estrutura percebida que, "baseada em experiências adquiridas, provoca uma série de sinestesias e me permite pensar em 'cerveja gelada num copo"' (ECO, 2007, p. 101). Os dados da experiência fornecidos pelo desenho funcionam da mesma forma que os dados da experiência fornecidos pela sensação: "seleciono-os e estruturo-os baseado em sistemas de expectativas e assunções oriundas da experiência precedente, e, portanto, com base em técnicas aprendidas, com base em códigos" (ECO, 2007, p. 101). Disso, podemos tirar que:

Os signos icônicos não 'possuem as propriedades do objeto representado', mas reproduzem algumas condições da percepção comum, com base nos códigos perceptivos normais e selecionando os estímulos que - eliminados os estímulos restantes - podem permitir-me construir uma estrutura perceptiva que possua - com base nos códigos da experiência adquirida - o mesmo 'significado' da experiência real denotada pelo signo icônico (ECO, 2007, p. 102).

É importante anotar, contudo, que esses semas sempre obedecem a determinadas convenções sociais dadas e, assim, "os signos icônicos reproduzem algumas condições da percepção do objeto, mas depois de tê-las selecionado com base em códigos de reconhecimento e anotado com base em convenções gráficas" (ECO, 2007, p. 104). É por isso que eu posso reconhecer o desenho "como sendo um "sol" mesmo que ele não tenha propriamente as características de seu referente (afinal, nenhuma teoria científica afirma que o astro seja formado por um círculo de onde partem retas em simetria), mas sim, as propriedades de uma outra representação esquemática.

A partir do que foi posto, pode-se destacar duas características principais dos signos icônicos: (1) eles podem denotar globalmente um perceptum em uma convenção gráfica simplificada e (2) ele não possui propriedades em comum com o objeto representado, mas sim, com o modelo perceptivo do objeto, ou seja, "é construível e reconhecível com base nas mesmas operações mentais que realizamos para construir o perceptum, independentemente da matéria em que essas operações se realizam" (ECO, 2007, p. 112).

É fundamental que, nesse ponto, façamos um parêntese acerca do termo perceptum. Trata-se de uma categoria lacaniana usada, fundamentalmente, para distinguir "o que percebe" (percipiens) do que é "percebido" (perceptum). A lógica da percepção envolvida nesses dois casos está no fato de que o primeiro atua como sujeito e o segundo enquanto significante. Dessa forma, o percipiens vem a ser efeito do perceptum (MILLER, 2005, p. 255-256).

Lacan propõe que o perceptum vem primeiro e que o percipiens é determinado por ele. Isso supõe que o perceptum é estruturado, é da ordem do significante, é uma estrutura ou uma cadeia significante, e o percepiens é um sujeito efeito do significante. O que implica que existam muitos; não se deve pensar o percepiens como uma função unitária: o sujeito, o percepiens do ouvido, não é o mesmo que o percepiens da visão. Neste sentido, temos uma teoria da percepção explodida (MILLER, 2005, p. 256).

Em outras palavras, ao retomar a orientação fenomenológica de incluir os sujeitos nos fenômenos, Lacan acentua o fato de que não pode haver um momento da percepção que esteja fora da estrutura simbólica da linguagem, uma vez que os dados puros estão desde sempre presos aos significantes. Como bem coloca Antonio Quinet, “o perceptum tem uma estrutura de linguagem, pois está na dependência do percipiens que habita um universo de discurso estruturador de sua realidade e suas percepções" (QUINET, 2002, p. 38).

O sujeito de Lacan, no entanto, é desde sempre um sujeito dividido e essa divisão repercute no percebido. Esse, portanto, também não é unívoco "na medida em que está estruturado por significantes que estruturam a experiência em si [...]. Por isso mesmo, a equivocidade própria do significante repercute na realidade percebida pelo sujeito" (QUINET, 2002, p. 38).

É preciso assinalar que a equivocidade do perceptum passa despercebida pelo sujeito, uma 
vez que a estrutura imaginária de sua formação faz crer um sujeito unificado. Antonio Quinet aponta, no entanto, que a divisão é mais evidente quando se escuta falar (uma vez que isso evocaria o Outro da fala). "A nível da percepção visual", no entanto, "a equivocidade do perceptum fica [ainda] menos manifesta devido ao poder unificador da imagem" (QUINET, 2002, p. 39).

O campo da percepção visual, para Lacan, é constituído por três registros fundamentais: o imaginário do espelho, o simbólico da perspectiva e o real da topologia. Diante disso, Quinet (2002, p. 43) aponta que:

o eu está para a visão como o sujeito inconsciente está para o olhar como objeto a. O eu, que equivale ao percipiens, vem usurpar o lugar do sujeito dividido do inconsciente, assim como o visto, o perceptum, vem barrar o olhar como objeto causa do desejo e da angústia.

Esse mecanismo pode ser melhor visualizado no esquema a seguir.

$$
\frac{\mathrm{Eu}}{\$}=\frac{\text { visto }}{\text { olhar }} \quad \frac{\text { percepiens }}{\$}=\frac{\text { perceptum }}{\mathrm{a}}
$$

É a partir desse esquema que Miller (2005, p. 256) pode afirmar que "Lacan introduziu o olhar na teoria da percepção visual, quando começou a interrogar o campo da percepção a partir do gozo". É ao tomar dessa ideia, também, que Umberto Eco identifica na comunicação visual os chamados "ícones gastronômicos", ou seja, semas visuais que, ao denotar o objeto representado, remetem ao gozo. Esses ícones ocorrem "quando uma qualidade de determinado objeto (camada gelada sobre o copo de cerveja, untuosidade de um molho, viço da pele feminina), em sua violenta representatividade, estimula diretamente o nosso desejo ao invés de limitar-se a denotar 'molho', 'gelo' ou 'maciez'" (ECO, 2007, p. 162).

Os mecanismos de estímulo do gozo proporcionado pelas imagens são regidos, prioritariamente, por mecanismos psicológicos de identificação (processos extrassemióticos, portanto). Eco marca, porém, o fato de que essa identificação é permitida graças a determinados elementos retóricos presentes nas imagens, que fazem de um caso isolado, proposto como convencionalmente reconhecível, algo universal e exemplar (podendo ser analisado, portanto, a partir de mecanismos semióticos).

A retórica da imagem se manifesta, por exemplo, através de alguns tropos como, para citar um caso, a participação mágica por aproximação. "Um homem moderno vestindo uma camisa anunciada, se aparecer ao lado de um quadro que representa um fidalgo setecentista, passa a participar - e com ele, o produto - da aura de nobreza, virilidade e dignidade do modelo clássico" (ECO, 2007, p. 163). É como se atributos de um objeto fossem transmitidos para o outro signo icônico com o objetivo de estabelecer um paralelo, em um mecanismo de transvalorização metafórica.

A partir desse mecanismo podemos explicar por que uma "marca - com sua imagem, sua estética, seu valor de gozo - é uma mercadoria que só tem valor pelos signos que precipita no imaginário. Nisso se encontra sua materialidade: sua materialidade de signo" (BUCCI, 2002b, p. 279). É através dessa transvalorização metafórica que determinada marca pode dotar seu produto de um valor imaginário que denota algo além de sua significação imediata (um valor, um estilo de vida, um ideário).

A publicidade, aliás, é um campo vasto de estudos para mostrar quão ricos podem ser os semas visuais, evocando, por vezes, blocos inteiros de premissas subentendidas, através de conotações do campo tópico:

Por exemplo: um iconograma do tipo 'ícone denotando jovem dona de casa que se inclina sobre um berço, sorrindo para um nenê que the estende os braços', conota, indubitavelmente (ao nível iconográfico), 'mamãezinha', mas ao mesmo tempo evoca um leque de persuasões do tipo 'as mães amam seus filhos - mãe é uma só - o amor de mãe é o mais forte - as mães adoram seus filhos - todos os filhos amam as suas mães - etc.' E mais: além dessas conotações, que constituem verdadeiras premissas, são conotados grupos argumentativos possíveis (e, portanto, 'lugares', no sentido estrito) do tipo 'se todas as mães são assim, por que vocês também não deveriam sê-lo?’ É fácil compreender como de um campo tópico desse gênero possam brotar entimemas como estes: 'todas as mães alimentam seus filhos com o 
produto $\mathrm{X}$ - quem alimenta seus filhos com o produto X faz aquilo que eles gostam (ECO, 2007, p. 164).

Como bem coloca Eco, esse jogo de remissões pode tomar a forma de uma antonomásia subentendida, uma vez que "aquela mãe" pode se transformar, potencialmente, em "todas as mães". É importante frisar, também, que os signos icônicos remetem também a campos entimemáticos, subentendendo "argumentações já convencionadas e reevocadas por uma imagem suficientemente codificada" (ECO, 2007, p. 165).

Esses mecanismos retóricos descritos por Eco ficam mais claros quando aplicados a algum produto específico. Tomemos como exemplo uma propaganda dos relógios "Orient" em que a atriz Juliana Paes aparece vestida em um elegante vestido preto ostentando um relógio dessa marca. A propaganda está ambientada em um museu ou em uma faculdade, combinando, dessa forma, a figura de uma mulher sedutora em um ambiente de sofisticação e erudição. Seguindo os passos de Eco, podemos dizer que o sema "Juliana Paes" se constrói a partir de uma complexidade conotativa crescente, em que uma conotação se apoia a outra: a mulher é bonita, é sedutora, é culta, é de bom gosto, é de uma classe social alta etc.

Ali, no entanto, ela não é a "Juliana Paes", mas sua personagem se veste de um valor antonomásico: ela é qualquer jovem bonita, sedutora, culta etc. Assim, ela se torna um modelo a serimitado uma vez que sua figura está carregada de conotações que a opinião social estabelece como prodigiosas. Como bem coloca Eco (2007, p. 167), "em certo sentido, as [...] imagens não são precedidas pelo quantificador universal 'todos', mas dele subentendem uma forma reduzida, do tipo 'todos aqueles que como vocês', a partir do momento em que a identificação ou a projeção se tenha verificado". E isso pode ser observado ainda que "a antonomásia subentendida estabeleça: 'este indivíduo são todos vocês, ou é aquele que vocês deveriam e poderiam ser" (ECO, 2007 , p. 167).

Além disso, por meio de mecanismos de ordem metafórica, podemos estabelecer também uma ideologia global conotada, que remete a determinados campos tópicos, como "ter sucesso na vida é ter sucesso mundano-erótico-econômico-intelectual". Nesse sentido, há uma redundância entre a vertente retórica e a vertente ideológica. Aí está a lógica do sujeito que goza por privar o outro.

Desta forma, podemos entender como a imagem apela para o mais-de-gozar imaginário. Resta pensarmos, no entanto, que essa somente se configura como mercadoria através da retribuição do olhar do outro. Ao juntar a perspectiva dos autores trabalhados, é a respeito desse assunto que trataremos no próximo tópico.

\section{A BUSCA PELO OLHAR: a transformação da imagem em mercadoria}

Seguindo o esquema proposto por Umberto Eco, portanto, podemos dizer que as imagens argumentam, as imagens buscam seduzir o leitor para persuadi-lo. Assim como em um texto (falado ou escrito), o orador busca conseguir a adesão da plateia para a ideia proposta através de uma série de estratégias retóricas, também as imagens operam o mesmo mecanismo.

Se adotarmos a proposta de Eugenio Bucci (2002b, p. 263) de que "para mercadoria, o valor do trabalho alienado (considerado a mais-valia) não é mais o único a lhe determinar o valor de troca. Há agora o valor de gozo, que antes seria um valor pressuposto, mas desprezível - e hoje é o valor central", a persuasão que essa imagem busca, no entanto, é de outra ordem que não as dos textos escritos. A adesão que a imagem busca não está tanto na ideia formulada pela propaganda (embora também esteja aí e também nesse local, enquanto imaginário, o valor de gozo se processe), mas se aloca, principalmente, na adesão do olhar. Pois é o olhar que a transforma em mercadoria. E isso porque o valor de gozo da mercadoria se compõe não apenas de trabalho, mas de algo mais:

Ele se compõe da combinação do trabalho com um segundo fator: de um lado, sim, compõe-se do trabalho fungível, além do trabalho criativo e do trabalho de inovação tecnológica (ambos menos fungíveis), estes dois representando a atividade humana que estabelece a diferença no imaginário superindustrial; de outro lado, o valor de gozo se compõe do olhar social, isto é, o capital se apropria do olhar para incorporá-lo aos signos que fabrica (BUCCI, 2002b, p. 263). 
As estratégias retóricas de uma imagem estão, portanto, todas voltadas para essa sedução do olhar. $\mathrm{E}$ isso a difere fundamentalmente da forma como um texto articula seus elementos retóricos. Além disso, podemos acrescentar nesse quadro as afirmações de Flusser a respeito da decodificação dos signos icônicos e da suposta consolidação da imagem como índice do real, através da ilusão referencial que engendra.

Embora esses mecanismos sejam mais facilmente analisáveis nas imagens publicitárias, eles não se limitam a elas. Susan Sontag (2003) mostra como existe mesmo um prazer "quase pornográfico" em se ver imagens de violência extrema. As imagens de dor intensas nos provocam, ao mesmo tempo, um deleite e uma angústia, na medida em que "não há nenhuma acusação moral que recai sobre a representação dessas crueldades. Apenas uma provocação: você é capaz de olhar para isso? Existe a satisfação de ser capaz de olhar para a imagem sem titubear. Existe o prazer de titubear" (SONTAG, 2003, p. 38).

E é por isso, de certa forma, que Sontag justifica o fato de que a iconografia do sofrimento humano tenha uma longa linhagem. "Os sofrimentos mais comumente considerados dignos de ser representados são aqueles tidos como frutos de ira, divina ou humana (o sofrimento decorrente de causas naturais, como enfermidade ou parto, é escassamente representado na história da arte)" (SONTAG, 2003, p. 37). E isso, de certa forma, se espelha em um sem número de programas televisivos que tem a violência como seu assunto principal.

$\mathrm{Na}$ teoria lacaniana, o mais-de-gozar é a expressão utilizada para nomear o pequeno objeto a no campo do gozo. "O objeto a, mais-de-gozar, se encontra como produto do discurso do mestre, laço instituidor correspondente à instauração da lei da civilização com a consequente exclusão do gozo ou, em termos freudianos, a conseqüente exigência da renúncia pulsional" (QUINET, 2002, p. 14). Como já havíamos posto anteriormente, o perceptum (enquanto estrutura imagética imaginária) está intimamente relacionado a essa busca do ser faltante pelo gozo ininterrupto.

E é nesses termos que Antonio Quinet pode associar o mais-de-gozar a um mais-de-olhar, na medida em que "a fenomenologia lacaniana inclui o desejo e o gozo no mundo da percepção e se instrui com a topologia: ela nos traz a estrutura de envelope do campo escópico que podemos mostrar com o cross-cap, superfície topológica que demonstra o real da estrutura na qual o sujeito se encontra em exclusão interna com seu objeto" (QUINET, 2002, p. 11).

Nesse sentido, a retórica da imagem se torna fundamental para seduzir o olhar do espectador na medida em que atua diretamente no perceptum. De uma forma geral, "é a pulsão escópica que confere o caráter de beleza ao objeto desejado do mundo sensível e permite que o sujeito 'o toque com os olhos' e o desnude com o olhar. O gozo escópico, a Schaulust que esta pulsão proporciona é o gozo dos espetáculos" (QUINET, 2002, p. 11). Como bem explica Quinet:

O olhar como objeto a éo que melhor demonstra o caráter agalmático do objeto causa do desejo. O agalma é sempre descrito por seu esplendor, sua beleza, como o que brilha qual uma jóia fulgurante na luz, qual o ponto de onde parte a luz, e assim também se pode representar o olhar como objeto a. O objeto agalmático vem representar o olhar como objeto a, em volta do qual a pulsão faz e volta e assim é causa do desejo para quem cair em sua armadilha. [...] O objeto olhar, enquanto objeto pulsional, emerge do campo do desejo do sujeito e veste a quem causar o desejo do sujeito de beleza, a pulsão agalmatiza o objeto ao vesti-lo de beleza (QUINET, 2002, p. 12).

Diante das perspectivas dos autores apresentados nesse trabalho, as viradas na metáfora foucautiana do Panóptico se justificam. O olhar, na sociedade atual, não é mais somente um modo de vigilância (embora seja ainda). Ela torna-se um olhar de gozo (imbuído dentro da lógica de um valor de gozo), um olhar de mais-gozar. Ao invés de punir, o olhar seduz; embora causador de constrangimentos, o Panóptico deixa de ser uma máquina de vigilância para ser mesmo uma máquina de consumo.

\section{REFERÊNCIAS}

BARTHES, R. El susurro del lenguaje. Barcelona: Paidós, 1988.

BAUMAN,Z. Globalização: as conseqüências humanas. Rio de Janeiro: Jorge Zahar, 1999. 
BUCCI, E. A fabricação de valor na superindústria do imaginário. Communicare, v. 2, n. 2, p. 55-72, 2002a.

Televisão objeto: a crítica e suas questões de método. 2002. 299 f. Tese (Doutorado em Ciências da Comunicação) - Escola de Comunicações e Artes da Universidade de São Paulo, São Paulo, 2002b.

ECO, U. A estrutura ausente. São Paulo: Perspectiva, 2007.

FLUSSER, V. O mundo codificado: por uma filosofia do design e da comunicação. São Paulo: Cosac Naify, 2007.

MILLER, J. A. Silet: os paradoxos da pulsão de Freud a Lacan. Rio de Janeiro: Jorge Zahar, 2005.

QUINET, A. Um olhar a mais: ver e ser visto na psicanálise. Rio de Janeiro: Jorge Zahar, 2002.

SMITH, D. Zygmunt Bauman: prophet of postmodernity. Cambridge: Polity Press, 1999.
SONTAG, S. Diante da dor dos outros. São Paulo: Companhia das Letras, 2003.

THOMPSON, J. B. A nova visibilidade. Matrizes, ano 1, n. 2, p. 15-37, 2008.
Recebido: 09/07/2009

Received: 07/09/2009

Aprovado: 16/07/2009

Approved: 07/16/2009

Revisado: 07/01/2010

Reviewed: 01/07/2010 